\title{
Review Paper: Drug Interactions of Psychiatric and COVID-19 Medications
}

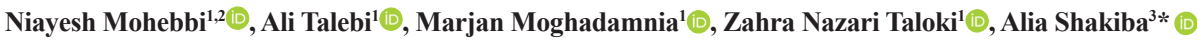 \\ 1. Department of Clinical Pharmacy, School of Pharmacy, Tehran University of Medical Sciences, Tehran, Iran. \\ 2. Research Center for Rational Use of Drugs; Tehran University of Medical Sciences, Tehran, Iran. \\ 3. Department of Psychiatry, Roozbeh Hospital, Tehran University of Medical Sciences, Tehran, Iran
}

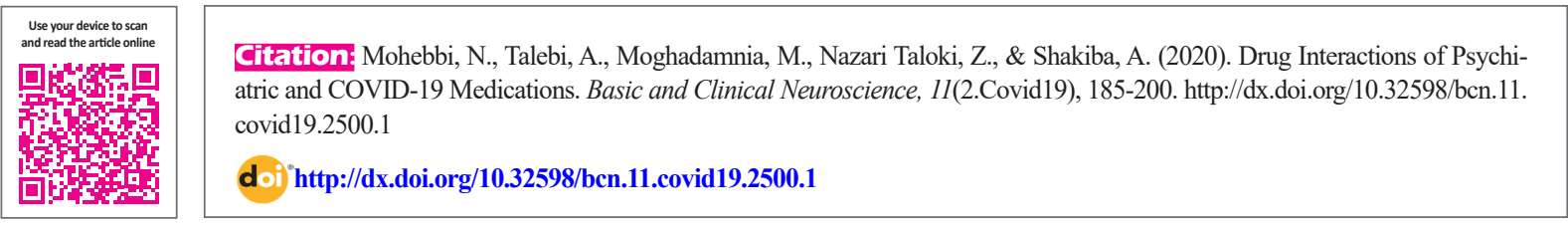

\section{(c) (1) (3)}

Article info:

Received: 16 Apr 2020

First Revision: 25 Apr 2020

Accepted: 26 Apr 2020

Available Online: 27 Apr 2020

Keywords:

COVID-19, Drug

interaction, Antidepressants, Antipsychotics, Anxiolytics, Chloroquine

\section{AB S T RA C T}

Introduction: Coronavirus disease 2019 (COVID-19) has become a pandemic with 1771514 cases identified in the world and 70029 cases in Iran until April 12, 2020. The co-prescription of psychotropics with COVID-19 medication is not uncommon. Healthcare providers should be familiar with many Potential Drug-Drug Interactions (DDIs) between COVID-19 therapeutic agents and psychotropic drugs based on cytochrome P450 metabolism. This review comprehensively summarizes the current literature on DDIs between antiretroviral drugs and chloroquine/hydroxychloroquine, and psychotropics, including antidepressants, antipsychotics, mood stabilizers, and anxiolytics.

Methods: Medical databases, including Google Scholar, PubMed, Web of Science, and Scopus were searched to identify studies in English with keywords related to psychiatric disorders, medications used in the treatment of psychiatric disorders and COVID-19 medications.

Results: There is a great potential for DDIs between psychiatric and COVID-19 medications ranging from interactions that are not clinically apparent (minor) to those that produce lifethreatening adverse drug reactions, or loss of treatment efficacy. The majority of interactions are pharmacokinetic interactions via the cytochrome P450 enzyme system.

Conclusion: DDIs are a major concern in the comorbidity of psychiatric disorders and COVID-19 infection resulting in the alteration of expected therapeutic outcomes. The risk of toxicity or lack of efficacy may occur due to a higher or lower plasma concentration of medications. However, psychiatric medication can be safely used in combination with COVID-19 pharmacotherapy with either a wise selection of medication with the least possibility of interaction or careful patient monitoring and management.

\footnotetext{
* Corresponding Author:

Alia Shakiba, PhD.

Address: Department of Psychiatry, Roozbeh Hospital, Tehran University of Medical Sciences, Tehran, Iran.

Tel: +98 (912) 2147743

E-mail:a_shakiba@sina.tums.ac.ir
} 


\section{Highlights}

- Drug interactions are major challenge in comorbidity of psychiatric disorders and COVID-19 infection

- QTc prolongation is a major concern while using antiviral medications and/or Chloroquine/hydroxychloroquine in combination with many psychotropics. Cardiac monitoring especially in high risk patients is highly recommended.

- Concomitant use of SSRIs with antiviral medications and/or Chloroquine/hydroxychloroquine increase the risk of hypoglycemia.

- Concomitant use of pimozide or midazolam with antiviral medications is contraindicated.

\section{Plain Language Summary}

In December 2019, the reports of Coronavirus Disease 2019 (COVID-19) were documented in Wuhan, China. This condition is caused by a novel beta-coronavirus, called as Severe Acute Respiratory Syndrome coronavirus 2 (SARSCoV-2). Nowadays, the Coronavirus Disease 2019 (COVID-19) has become a global pandemic; with more than hundred thousand cases have been identified in Iran. COVID-19 affects people's mental health and quality of life. The COVID-19 causes panic, anxiety, depression and insomnia, especially in patients and health care professionals. There is a possibility of starting psychiatric drugs in patients with COVID-19. Also, some patients with COVID-19 have been taking psychiatric drugs due to various problems. As a result of this, the likelihood of drug- drug interaction (DDI) between psychiatric drugs and drugs used to treat COVID-19 can be a concern. Many psychiatric drugs are metabolized via the cytochrome P450 system. Therefore, their hepatic metabolism and ability to alter activity of cytochrome P450 can lead to pharmacokinetic interactions when they are used with medications in COVID-19 treatment. Risk of toxicity or lack of efficacy may occur due to higher or lower plasma concentration of medications. Moreover intensification of similar adverse effects might lead to patients harm. Psychiatric medication can be safe in combination with COVID-19 pharmacotherapy with close attention to selection of medication with the least possibility of interaction and also careful monitoring.

\section{Introduction}

I

$\mathrm{n}$ December 2019, the reports of coronavirus disease 2019 (COVID-19) were documented in Wuhan, China (Guan et al., 2020). This condition was caused by a novel beta-coronavirus, called severe acute respiratory syndrome coronavirus 2 (SARS-CoV-2) (Lai, Shih, Ko, Tang, \& Hsueh, 2020). Coronaviruses are enveloped, positive-stranded RNA viruses, with a single-stranded genome between $27 \mathrm{~kb}$ and $31.5 \mathrm{~kb}$, the largest among known RNA viruses (Di Paola \& Giuliani, 2020). Coronavirus family belongs to Nidovirales order and causes gastrointestinal and upper respiratory tract diseases in humans and animals (Chen, Sugiyama, Kubo, Huang, \& Makino, 2004).

Nowadays, the Coronavirus Disease 2019 (COVID-19) has become a pandemic (Tuite et al., 2020). According to the World Health Organization, As of April 12, 2020, 1771514 cases have been identified in the world and 70029 cases in Iran. About $80 \%$ of patients show a minor illness while $14 \%$ have severe and $5 \%$ critical conditions (Wu \& McGoogan, 2020).

COVID-19 also affects people's mental health and quality of life. The COVID-19 causes panic, anxiety, depression, and insomnia, especially in patients and health care professionals (Li et al., 2020; Nguyen et al., 2020). The first suicide was reported in India due to poor adjustment following the diagnosis of COVID-19 (Goyal, Chauhan, Chhikara, Gupta, \& Singh, 2020). So, there is some caution in using psychotropics in patients with COVID-19. Also, some patients with COVID-19 have been taking psychotropics due to various problems. As a result, the likelihood of Drug-Drug Interaction (DDI) between psychotropics and COVID-19 drugs can be a concern.

The interactions between psychotropics and COVID-19 drugs are mainly in two ways: first, pharmacokinetic drug-drug interactions i.e. one drug alters the disposition of a co-administered agent and second, compounding of side effects (Leveque et al., 2010). Cytochrome P450 
plays a key role in the metabolism of medications and their interactions (Ogu \& Maxa, 2000). For example, the hepatic CYP isoenzymes, which are responsible for metabolizing the tricyclic antidepressants consisting of 2D6, 1A2, 3A4, 2C19 (Gillman, 2007). Most first- and second-generation antipsychotics are metabolized by the cytochrome P450 system mainly include 2D6, 1A2, and 3A4 (Wijesinghe, 2016). On the other hand, some Selective Serotonin Reuptake Inhibitors (SSRIs) are cytochrome P450 inhibitors and can result in DDIs by changing the blood concentration of the drugs activated or metabolized by these enzymes (Preskorn, 1997). Therefore, their hepatic metabolism and ability to alter the activity of cytochrome P450 can make pharmacokinetic interactions when they are used with medications in COVID-19 treatment.

The purpose of this review is to comprehensively explore DDIs, especially pharmacokinetic DDIs between psychotropic medications and COVID-19 medications. Also, we try to find the adverse effects and clinical issues that must be considered for combined medication regimens in psychiatry.

\section{Methods}

\subsection{Search strategy}

For this narrative review, the relevant articles published from 2000 to April 2020 were searched in Google Scholar, PubMed, Web of Science, and Scopus databases. The articles were limited to the English language. The keywords used in titles and abstracts were depression or anxiety, psychosis or psychiatric disorders and specific names of medications used in the treatment of psychiatric disorders, antidepressants, antipsychotics, anxiolytics, or mood stabilizers, as well as psychotropic medication in combination with pharmacological treatments of COVID-19 i.e. chloroquine, hydroxychloroquine, ritonavir, lopinavir, or Kaletra. Article references were also checked to find additional relevant studies.

The inclusion criteria were any type of study, including reviews and systematic reviews, clinical trials and case reports with the subject of drug-drug interactions of any psychotropic drug with ritonavir, lopinavir, or Kaletra and or chloroquine/hydroxychloroquine with a study population of either healthy volunteers or patients with HIV/AIDS, hepatitis, or malaria.

Articles' titles and abstracts were reviewed for relevant information by two reviewers and the discrepancies were checked with the first author.
In total, 30 studies met the inclusion criteria. All publications were reviewed in full text by the researchers.

\subsection{Antidepressants}

\subsubsection{Selective serotonin reuptake inhibitors}

The Selective Serotonin Reuptake Inhibitors (SSRIs) are used to treat major depressive disorder, anxiety, and some other psychiatric disorders. All SSRIs are metabolized by cytochrome P450 enzymes and some of them (such as fluoxetine) can inhibit these enzymes. Therefore, SSRIs' interactions with other cytochrome P450 substrates should be considered (DEPRESSION).

Fluoxetine is one of the most recommended SSRIs. The utmost amount of fluoxetine N-demethylation is mediated by CYP2D6, CYP2C9, CYP2C19, and CYP3A4. Fluoxetine and its active metabolite (nor-fluoxetine) inhibit CYP2D6 (strong), CYP2C9 (moderate), CYP2C19 (weak to moderate), CYP3A4 (weak to moderate), and CYP1A2 (weak) (Jin et al., 2016; Margolis, O’Donnell, Mankowski, Ekins, \& Obach, 2000). Fluoxetine and its metabolites increase the Area Under The Curve (AUC) of ritonavir by up to $19 \%$ through inhibiting CYP2D6 and CYP3A4 (especially CYP2D6) without significant change in other kinetic parameters of ritonavir. This relatively low drug-drug interaction does not need dose modification (Ouellet et al., 1998). On the other hand, there is a possibility of serotonin syndrome in concomitant use of ritonavir with SSRIs. Desilova et al. reported four cases of serotonin syndrome as a result of the coadministration of ritonavir and fluoxetine (DeSilva, Le Flore, Marston, \& Rimland, 2001). Fluoxetine as a CYP2D6 inhibitor (strong) may decrease the metabolism of CYP2D6 substrates like chloroquine and hydroxychloroquine (Bjornsson et al., 2003). Consequently, the side effects of chloroquine and hydroxychloroquine should be considered.

Paroxetine is metabolized mainly by CYP2D6 (high affinity) and CYP3A4 (low affinity) and partially by CYP1A2, CYP2C19, and CYP3A5. Its protein binding is 95\% and can inhibit the CYP2D6 enzyme (Jornil, Jensen, Larsen, \& Linnet, 2010). In Manon.et al. study, 26 healthy participants were given paroxetine $(20 \mathrm{mg} / \mathrm{d})$ and fosamprenavir/ritonavir (700 mg/100 mg twice daily) for 10 days. They found that paroxetine levels dropped by an average of 55\% compared with when it was used alone because of protein binding displacement (Van Der Lee et al., 2007). 
Citalopram and S-enantiomer of citalopram (escitalopram) are metabolized by CYP3A4, CYP2C19, and CYP2D6. They both have a weak inhibitory effect on CYP2D6 (von Moltke et al., 2001). Ritonavir inhibits CYP 3A4 but the interaction with citalopram and its active $\mathrm{S}$-enantiomer is not clinically significant. In a study by Marcelo on 21 healthy volunteers who received daily escitalopram $(20 \mathrm{mg})$ and ritonavir $(600 \mathrm{mg})$, there was no significant change in the pharmacokinetic profile of escitalopram except for the volume of distribution, which decreased by $10 \%$ during concomitant use with ritonavir (Gutierrez, Rosenberg, \& Abramowitz, 2003). Nonetheless, ketoconazole as a potent CYP3A4 inhibitor did not alter the pharmacokinetics of citalopram, indicating that ketoconazole and other CYP3A4 inhibitors may potentially be safe with citalopram and no dose adjustment is necessary, although this issue has not been studied explicitly (Gutierrez \& Abramowitz, 2001). Citalopram and escitalopram inhibit CYP2D6 (weak), so it does not appear to cause significant changes in ritonavir levels (Hill \& Lee, 2013).

Medications like citalopram/escitalopram and chloroquine/hydroxychloroquine are known for causing cardiac complications (such as QTc prolongation). Possibility of this complication seemed additive and can be aggravated in the presence of further risk factors, such as old age, cardiac disease, electrolyte disturbances (hypokalemia, hypomagnesemia), and bradycardia. If there is no alternative medicine, co-administration of these drugs must be done with monitoring the patient's clinical symptoms and Electrocardiogram (ECG) (Meid et al., 2017). Citalopram may enhance the hypoglycemic effect of hydroxychloroquine. Results of two case-control studies show that consuming SSRIs, especially for more than 3 years in people treated with blood sugar lowering agents increases the risk of hypoglycemia (Derijks et al., 2008; Derijks et al., 2008).

CYP2D6, CYP3A4, CYP2B6, CYP2C9, and CY$\mathrm{P} 2 \mathrm{C} 19$ are involved in sertraline metabolism (Axelson et al., 2002). Sertraline inhibits CYP2D6 with less potency than fluoxetine and paroxetine (Liston et al., 2002). Sertraline may enhance the risk of hypoglycemia when co-administered with agents that have blood glucose effects like chloroquine/hydroxychloroquine. A review article explains available case reports of hypoglycemia and hyperglycemia associated with some SSRIs (fluoxetine, paroxetine, fluvoxamine, and sertraline) (Khoza \& Barner, 2011). Ritonavir is a strong inhibitor of CYP3A4. Ritonavir can increase the level of drugs eliminated by CYP3A4 metabolism (Hsu, Granneman, \& Bertz, 1998)
CYP1A2 and CYP2D6 are two CYPP450 isozymes that metabolize fluvoxamine. Fluvoxamine inhibits CYP1A2 (major), and CYP3A4 (moderate), and CYP2D6 (minor) (van Harten, 1995). Fluvoxamine can increase the level of CYP3A4 substrates (e.g. ritonavir), and this effect should be considered especially when used simultaneously with some drugs that have a narrow therapeutic window (DeVane \& Gill, 1997).

There is no interaction between SSRIs and ribavirin. It may increase dizziness but not much (Hou, Xu, Wang, \& Yu, 2013). Cardiotoxicity caused by chloroquine/hydroxychloroquine can be serious and life-threatening in high-risk patients. Therefore, in people with underlying heart diseases, old age, female gender, congenital long QT syndrome, and electrolyte imbalances, including hypokalemia and hypomagnesemia, it is best to monitor the clinical symptoms with the electrocardiogram (Tönnesmann, Kandolf, \& Lewalter, 2013).

SSRIs (fluoxetine, paroxetine, citalopram, sertraline) and SNRIs (venlafaxine) can cause cardiomyopathy and QTc prolongation (Kim, Alsherdini, Chang, \& Abela, 2013).

SSRIs may cause hypoglycemia via different mechanisms, such as an increase in insulin sensitivity, interaction with sulfonylureas in their metabolism, and a decrease in gluconeogenesis (Derijks et al., 2008; Ghaeli et al., 2004; Han et al., 2016; Santra, Banerjee, Munshi, \& Chaudhuri, 2015). Hydroxychloroquine can induce symptomatic or asymptomatic hypoglycemia in diabetic and nondiabetic patients (Unübol, Ayhan, \& Guney, 2011). Also, chloroquine can lead to hypoglycemia by increasing glucose uptake in muscle cells and stimulating glycogen synthesis (Halaby, Kastein, \& Yang, 2013). Thus, one should contemplate further monitoring of glycemic control in patients receiving an agent with blood glucose-lowering effects concurrently with an SSRI and chloroquine or hydroxychloroquine.

\subsubsection{Serotonin-norepinephrine reuptake inhibitors}

Serotonin-Norepinephrine Reuptake Inhibitors (SNRIs) are used to treat depressive disorders (e.g. dysthymia), anxiety disorders (e.g. panic disorder, general anxiety disorder, and social anxiety disorder), and chronic pain syndromes, such as diabetic peripheral neuropathy (Nelson, 2019).

Venlafaxine is metabolized mainly by CYP2D6 and CYP3A4 and partially by CYP2C19. It does not affect (inhibit or induce) CYP450 microsomes. Venlafaxine 
may cause arrhythmia associated with QTc prolongation in high-risk people (e.g. those who use drugs that prolong QT intervals like chloroquine and hydroxychloroquine, preexisting cardiac disease, old age, female sex, electrolyte imbalance, etc.). In the case of concurrent use of several medications associated with QT interval prolongation, close monitoring, and careful clinical assessment should be done (Howell, Wilson, \& Waring, 2007). In a study investigating 21 healthy participants on venlafaxine and potent CYP3A4 inhibitor ketoconazole, it was found that levels of venlafaxine increased with the concomitant use of ketoconazole (Lindh, Annas, Meurling, Dahl, \& Ayman, 2003). Also, ritonavir has a strong inhibitory effect on CYP3A4.

Duloxetine is metabolized by CYP1A2 and CYP2D6. It has a moderate inhibitory effect on CYP2D6. In a study ion the effect of duloxetine on CYP2D6, healthy volunteers used desipramine (CYP2D6 substrate) and paroxetine (a CYP2D6 inhibitor) along with duloxetine. The results indicated that desipramine levels were 2.9 times higher than when administered alone. On the other hand, concomitant use of duloxetine with paroxetine leads to increased levels of duloxetine. Side effects of duloxetine alone or in combination with desipramine or paroxetine were similar. Chloroquine may affect the concentration of duloxetine by inhibiting CYP2D6 (Skinner et al., 2003). Despite the inhibitory effect on CYP2D6 and induced CYP1A2 by ritonavir, concomitant use of duloxetine with ritonavir is allowed (Smolders et al., 2016).

\subsubsection{Serotonin modulators}

Trazodone is used for the treatment of major depressive disorder, anxiety disorder, and obsessive-compulsive disorder (Bossini et al., 2015). The metabolism of trazodone in humans is mediated through CYP3A4 and CYP2D6. Trazodone does not affect the activity of CYP isozymes (Zalma et al., 2000). Trazodone peak plasma concentration and the AUC significantly increase $34 \%$ and $137 \%$, respectively in concomitant use with ritonavir (a CYP3A4 inhibitor). Trazodone elimination half-life was prolonged $122 \%$ and oral clearance decreased $52 \%$ by ritonavir. Drowsiness, lethargy, and performance impairment also increased in co-administration with ritonavir, also three subjects experienced nausea, dizziness, and hypotension (Zalma et al., 2000). In a case report, a patient was treated with fluoxetine, diazepam, and trazodone went to the emergency room with sedation, dizziness, and nausea after taking 60 units trazodone, which showed a QTc prolongation in her ECG (Levenson, 1999). Thus, additive effects (e.g. some potent CYP450 3A4 inhibitors like ritonavir, chloroquine, hydroxychloroquine) may result in QTc prolongation when used with trazodone (Tönnesmann et al., 2013).

\subsubsection{Norepinephrine-serotonin modulator}

Mirtazapine is metabolized by CYP1A2, CYP3A4, and CYP2D6 (Gillman, 2007) and ritonavir boosted lopinavir is a CYP3A4 inhibitor (Lim et al., 2004). Clinically significant interactions between mirtazapine and ritonavirboosted lopinavir have not been reported. However, it is suggested that the lowest efficient dose of mirtazapine be used when it is co-administered with CYP3A4 inhibitors (Goodlet, Zmarlicka, \& Peckham, 2019). No interaction has been found between mirtazapine and hydroxychloroquine, chloroquine, ribavirin, and interferons.

\subsubsection{Norepinephrine-dopamine reuptake inhibitor}

Bupropion is classified as a dopamine norepinephrine reuptake inhibitor and used to treat major depression and other mood disorders (Horst \& Preskorn, 1998). Bupropion is metabolized by CYP2B6 isoenzyme to hydroxybupropion (Spina, Pisani, \& de Leon, 2016) and CYP2B6 inducers such as ritonavir may decrease its serum concentration (Hesse, von Moltke, Shader, \& Greenblatt, 2001). In one study on 12 healthy volunteers, the ritonavir boosted lopinavir at the standard dose (400 mg/100 mg twice daily) and reduced the bupropion AUC by 57\% (Hogeland et al., 2007). Another study showed the ritonavir administration at high (600 mg twice daily) and low (100 mg twice daily) doses resulted in $67 \%$ and $22 \%$ reductions in bupropion concentrations, respectively (Park et al., 2010). This interaction can occur only 3 days after starting ritonavir (Kharasch, Mitchell, Coles, \& Blanco, 2008). In contrast, one study indicated that short-term use of ritonavir had minimal impact on bupropion pharmacokinetics (Hesse, Greenblatt, von Moltke, \& Court, 2006). We suggest that the clinical effectiveness of bupropion is monitored and a higher dose may be required.

No study or case report has documented the DDI between bupropion and chloroquine but theoretically, there is a pharmacokinetic interaction. Bupropion is a strong CYP2D6 inhibitor (Kotlyar et al., 2005; Xue, Zhang, \& Cai, 2017) and chloroquine is a CYP2D6 substrate. Thus bupropion may decrease the metabolism of chloroquine. We think that this interaction may be clinically unimportant because chloroquine can be metabolized by other isoenzymes like CYP2C8 and CYP3A4 with low-affinity, high-capacity systems (Projean et al., 2003). There is no study and case report about bupropion interaction with other drugs that are used for the treatment of COVID-19. 


\subsubsection{Tricyclic antidepressants}

In 1958, Tricyclic Antidepressants (TCAs) were introduced to the world by using imipramine for melancholic depression (Kuhn, 1958). This class was the first-line treatment for depression until the SSRIs were introduced. Nevertheless, tricyclic antidepressants continue to be used to treat many other psychiatric disorders there with depression (Gelenberg et al., 2010). The principle site for metabolism and elimination of TCAs is the liver. These drugs are metabolized through the hepatic CYP isoenzymes, mainly CYP2D6, CYP1A2, CYP3A4, and CYP1C19 (Gillman, 2007). Since protease inhibitors such as ritonavir can inhibit CYP2D6 and CYP3A4, the serum concentration of TCAs may increase. In one study on the effect of low-dose ritonavir on the activity of cytochrome P450, the CYP2D6 dose of $100 \mathrm{mg}$ twice daily of ritonavir increased $26 \%$ in the AUC of desipramine. Low-dose ritonavir which is present in combination product of lopinavir/ritonavir has a medium inhibitory effect on the function of CYP2D6. Therefore, it seems that dose reduction is not necessary and only the patient should be monitored for toxic effects of TCAs (Aarnoutse et al., 2005).

No interaction has been reported between TCAs and hydroxychloroquine, although it is possible due to the risk of QT interval prolongation with both hydroxychloroquine and TCAs. So, there is a potential drug-drug interaction between them (Norman, Dunn, Bakker, Allen, \& De Albuquerque, 2013). The same is true for chloroquine.

\subsubsection{Monoamine Oxidase Inhibitors (MAOIs)}

Monoamine Oxidase Inhibitors (MAOIs) are not the first-line drugs for the treatment of depression because of their side effect profile and drug-drug and food-drug interactions. Nevertheless, this class may be used in resistant depression (Yamada \& Yasuhara, 2004). No interaction has been reported between MAOIs and hydroxychloroquine, but several articles reported the hypoglycemic effect of MAOIs (Cooper \& Ashcroft, 1966; Wickström \& Pettersson, 1964) and hydroxychloroquine (Cansu \& Korkmaz, 2008; De-Heer \& Doherty, 2018; Shojania, Koehler, \& Elliott, 1999; Unübol et al., 2011). Hypothetically, their co-administration may lead to hypoglycemia. Therefore, it is recommended that susceptible patients be monitored for signs and symptoms of hypoglycemia. Similar to hydroxychloroquine, the effect of lowering blood glucose has been reported for chloroquine (Goyal \& Bordia, 1995; Mostafavi, 1998; Phillips et al., 1986). Thus, concomitant use of chloroquine with MAOIs may cause hypoglycemia like hydroxychlo- roquine. So far no study has not been published about the interaction between MAOIs and protease inhibitors, ribavirin, and interferons.

Among antidepressants, fluoxetine and paroxetine have the greatest inhibitory effect on CYP2D6; fluvoxamine strikingly inhibits CYP1A2 and CYP2C19. Hence, when these medications are prescribed with substrates of the relevant isozymes together, clinically interactions may be anticipated, especially those with a narrow therapeutic range. Duloxetine, sertraline, and bupropion inhibit CYP2D6 moderately, but sertraline at a high dose may have more potency to inhibit CYP2D6. Citalopram, escitalopram, venlafaxine, mirtazapine have a weak or negligible inhibitory effect on CYP isozymes in vitro, so significant interactions are less likely to occur with concomitant use of this cytochrome's substrates (Spina, Santoro, \& D'Arrigo, 2008).

\subsubsection{Newer antidepressants}

Lopinavir and ritonavir can potentially increase the level of vortioxetine by affecting CYP2D6 (Spina, Pisani, $\&$ de Leon, 2016). The clinical significance of this interaction is unknown as there is no published report about their co-administration.

Similarly, both ritonavir and lopinavir can increase the level of vilazodone by affecting the CYP3A4 (Spina, Pisani, \& de Leon, 2016). The interaction may be serious and $50 \%$ vilazodone dose reduction or using an alternative is suggested (Boinpally, Gad, Gupta, \& Periclou, 2014). There is no interaction between the above-mentioned antidepressants and chloroquine or hydroxychloroquine.

\subsubsection{Mood stabilizers}

Mood stabilizers, including lithium, lamotrigine, valproic acid, and carbamazepine are mainstay drugs for the treatment of patients with bipolar disorders in the acute and maintenance phase (Gould, Chen, \& Manji, 2002).

\subsubsection{Lamotrigine}

Lopinavir may decrease the serum concentration of lamotrigine because lopinavir/ritonavir induces Uridine Diphosphate Glucuronosyltransferases (UGTs), enzymes responsible for lamotrigine metabolism. Lamotrigine efficacy and toxicity symptoms, including skin rash and hematologic toxicities should be closely monitored in their coadministration. One study on 24 healthy participants who received lamotrigine (100 mg BD) in combination with 
Kaletra (400 mg/100 mg BD) showed a 50\% reduction in half-life, AUC, and Cmin. Also, lamotrigine clearance increased by approximately $85 \%$ (van der Lee et al., 2006). Accordingly, concomitant administration of lamotrigine with Kaletra that is a glucuronidation inducer may decrease lamotrigine concentrations so dose increase is recommended for dose titration.

\subsubsection{Valproic acid}

Valproic acid is metabolized by three pathways of extensive UGT glucuronidation (UGT1A6, UGT1A9, UGT2B7), mitochondrial $\beta$-oxidation, and minimal cytochrome P450-mediated oxidation. UGT enzyme inhibitors or inducers can increase or reduce serum concentrations of valproic acid, respectively. Sheehan NL et al. reported a patient with bipolar disorder in maintenance treatment with valproic acid who experienced mania symptoms a few days after initiating antivirals regimen ritonavir and lopinavir, potentially due to decrease in the serum concentration of valproate product (Ethell, Anderson, \& Burchell, 2003; Sheehan, Brouillette, Delisle, \& Allan, 2006). Also according to the NIH guidelines, lopinavir AUC increases by approximately $75 \%$ with concomitant valproic acid use. Therefore, patients under combination therapy should be monitored for lopinavir toxicity and virologic response (Dybul, Fauci, Bartlett, Kaplan, \& Pau, 2002). In two studies, the reduced valproate concentrations were observed in patients treated with valproic acid and lopinavir/ritonavir (DiCenzo et al., 2004; Sheehan et al., 2006).

\subsubsection{Carbamazepine}

Carbamazepine is both a substrate and a potent inducer of CYP3A4. Higher doses of lopinavir as a substrate for CYP450-3A4 may be necessary in combination with carbamazepine and close monitoring should be provided (Hill \& Lee, 2013).

Chloroquine is metabolized via CYP3A4 (Ducharme \& Farinotti, 1996). Therefore, concomitant use of chloroquine with a CYP3A4 inducer, such as carbamazepine appears to reduce chloroquine levels and dose adjustment is offered.

\subsubsection{Lithium}

Lithium is excreted unchanged in the urine and has no known effects on CYP enzymes. Hence it is the least likely mood stabilizer that has DDIs with antiretroviral drugs (Thompson, Silverman, Dzeng, \& Treisman, 2006). However, it is rational to inspect patients for interactions. No interaction has been reported between mood stabilizers with ribavirin and hydroxychloroquine.

\subsubsection{Antipsychotics}

Antipsychotics are the main drugs for the treatment of schizophrenia. The principle site of metabolism of most antipsychotics (the first and second-generation) is CYP isoenzymes, in particular CYP3A4 and CYP2D6. Therefore, DDIs in combined use with drugs that have a strong effect on CYP pathway metabolism such as CYP450, CYP3A4, CYP2D6 inducer, and inhibitors are possible (Hill \& Lee, 2013; Lally \& MacCabe, 2015). Protease inhibitors such as Kaletra (ritonavir/lopinavir) are strong CYP3A4 inhibitors and affect the activity of cytochrome resulting in antipsychotic accumulation and toxicity (Corbett, Lim, \& Kashuba, 2002; Jernigan, Kipp, Rather, Jenkins, \& Chung, 2013; Wyen et al., 2008).

\subsubsection{Aripiprazole}

Aripiprazole is a substrate of CYP2D6 and CYP3A4, and ritonavir is a strong inhibitor of these two enzymes (Azuma et al., 2012; Hendset, Hermann, Lunde, Refsum, \& Molden, 2007; Kirby et al., 2011; Preskorn, 2012; Sheehan, Sliwa, Amatniek, Grinspan, \& Canuso, 2010; Suzuki et al., 2011; Urichuk, Prior, Dursun, \& Baker, 2008; Wyen et al., 2008). Concomitant use of aripiprazole and ritonavir has the potential additive effect on metabolic disturbances and increases the adverse/ toxic effects of ritonavir that should be monitored. Aripiprazole dose adjustment (reduced dose) is often appropriate in patients with CYP2D6 poor metabolizers or when combined with a CYP2D6 inhibitor or a CYP3A4 inhibitor (Hill \& Lee, 2013).

\subsubsection{Olanzapine}

The serum concentration of olanzapine may be decreased by ritonavir (dose depending) because of ritonavir induction of CYP1A2 and or glucuronosyltransferase-mediated olanzapine metabolism. In a study on 14 healthy volunteers, ritonavir dose tapered up gradually and reduced the olanzapine Cmax, AUC, and half-life by $40 \%, 53 \%$, and $50 \%$, respectively (Hill \& Lee, 2013; Jacobs, Colbers, VelthovenGraafland, Schouwenberg, \& Burger, 2014; Penzak et al., 2002).

\subsubsection{Quetiapine}

Ritonavir is a strong CYP3A4 inhibitor that has an inhibitory effect on quetiapine metabolism and may increase its serum concentration and adverse reactions 
(Hill \& Lee, 2013; Pollack, McCoy, \& Stead, 2009). Therefore, it is best to reduce the dose of quetiapine and monitor it closely.

\subsubsection{Ziprasidone}

Protease inhibitors (e.g. ritonavir) with CYP3A4 inhibitory property can increase the level of ziprasidone. Therefore, it needs more monitoring (Hill \& Lee, 2013; Manini, Raspberry, Hoffman, \& Nelson, 2007).

\subsubsection{Clozapine}

There are overlap metabolic toxicities (e.g. hyperglycemia, weight gain, hyperlipidemia) with clozapine and all of the protease inhibitors. So their administration should be monitored or alternative agents be considered (Hill \& Lee, 2013).

\subsubsection{Chlorpromazine}

Chlorpromazine is a typical antipsychotic agent that was first developed in 1951. Chlorpromazine is a high-risk drug for QT-prolongation and chloroquine increased its serum concentrations 3 hours after an oral dose in patients under treatment (Makanjuola, Dixon, \& Oforah, 1988).

\subsubsection{Pimozide}

Pimozide is an antipsychotic and CYP3A4 substrate. Its co-administration with ritonavir should be avoided because of increasing pimozide levels and the risk of QTc prolongation (Hill \& Lee, 2013). QT prolongation is a cardiovascular side effect of pimozide (Kräuhenbühl et al., 1995). Therefore, we should avoid concomitant use with medications that can affect QT interval (e.g. chloroquine).

\subsubsection{Risperidone}

CYP2D6 and CYP3A4 are the main sites for risperidone metabolism. Ritonavir is a strong inhibitor for both enzymes. Studies have shown that co-administration of these drugs increases the side effects of risperidone (Jover, Cuadrado, Andreu, \& Merino, 2002; Kelly, Béïque, \& Bowmer, 2002).

Antipsychotics, especially ziprasidone and quetiapine have the potential to increase QT interval (Hill \& Lee, 2013). Theoretically, concomitant use of antipsychotics like ziprasidone and quetiapine with chloroquine or hydroxychloroquine can increase the risk of QTc prolongation. No interaction has been reported between antipsychotic drugs and ribavirin.

\subsection{Anxiolytics}

\subsubsection{Benzodiazepines}

Benzodiazepines (BZDs) are a group of psychotropic medications with sedative, hypnotic, and anxiolytic effects that are metabolized via CYP450 enzymes particularly subtype CYP3A4 in the liver (Griffin, Kaye, Bueno, \& Kaye, 2013; Riss, Cloyd, Gates, \& Collins, 2008). Therefore, medications with CYP3A4 inhibitory effect like Kaletra (ritonavir/lopinavir) that is a strong CYP3A4 inhibitor may decrease the metabolism of a CYP3A4 substrate such as chlordiazepoxide, diazepam, clonazepam, flurazepam, triazolam, midazolam, and alprazolam. The patient should be monitored closely and even using an alternative agent with lower interaction (e.g. lorazepam, oxazepam, and temazepam) or dose adjustments should be considered (Dybul et al., 2002).

\subsubsection{Midazolam}

Midazolam is a CYP3A4 substrate (Ieiri et al., 2013; Kronbach, Mathys, Umeno, Gonzalez, \& Meyer, 1989). Some studies have reported AUC increase ( 5 to 28 fold) or reduction in oral and intravenous midazolam clearance $(65 \%-96 \%)$ after co-administration with ritonavir or Kaletra (ritonavir/lopinavir) (Greenblatt et al., 2000; Greenblatt et al., 2003; Knox et al., 2008; Mathias, West, Hui, \& Kearney, 2009; Schmitt, Hofmann, Riek, Zwant ziger, \& Patel, 2009; Yeh et al., 2006).

\subsubsection{Diazepam}

Diazepam is metabolized via CYP3A4, and to a smaller extent via CYP2C19 (Kakuda, Schöller-Gyüre, \& Hoetelmans, 2011). Therefore co-administration of diazepam with ritonavir can decrease diazepam metabolism and in combination therapy, the lower dose of diazepam is recommended (Dybul et al., 2002).

\subsubsection{Alprazolam}

Alprazolam is a benzodiazepine metabolized via CYP3A4 (Frye et al., 1997). In some studies, the AUC of alprazolam increased by approximately 2.5 fold and causes increased sedation and psychomotor performance impairment with ritonavir co-administration (Hesse, von Moltke, \& Greenblatt, 2003).

\subsubsection{Triazolam}

Also, triazolam metabolism is via CYP3A4 isoenzyme (Kronbach et al., 1989). A study has shown that clearance of triazolam reduced when co-administered 
Table 1. Summary of drug-drug interaction between psychotropics and pharmacological treatments used for COVID-19

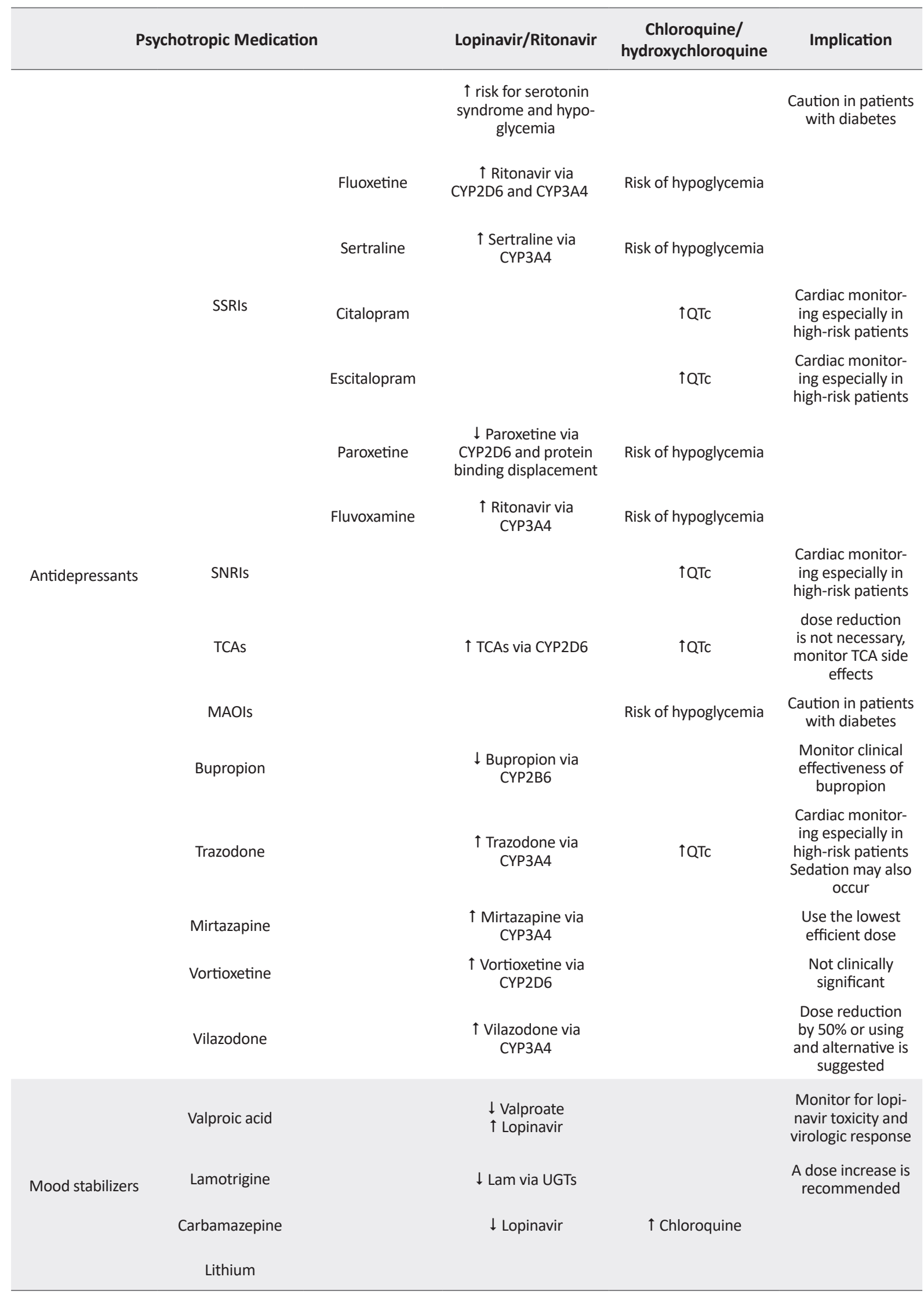




\begin{tabular}{|c|c|c|c|c|c|}
\hline \multicolumn{3}{|c|}{ Psychotropic Medication } & Lopinavir/Ritonavir & $\begin{array}{c}\text { Chloroquine/ } \\
\text { hydroxychloroquine }\end{array}$ & Implication \\
\hline \multirow{8}{*}{ Antipsychotics } & \multirow{6}{*}{$\begin{array}{l}\text { Second-generation } \\
\text { antipsychotics }\end{array}$} & Risperidone & $\begin{array}{l}\uparrow \text { Risperidone via } \\
\text { CYP3A4 and 2D6 }\end{array}$ & & \multirow{3}{*}{ Dose reduction } \\
\hline & & Aripiprazole & $\begin{array}{l}\uparrow \text { Aripiprazole via } \\
\text { CYP3A4 and 2D6 }\end{array}$ & & \\
\hline & & Olanzapine & $\begin{array}{l}\downarrow \text { Olanzapine via } \\
\text { CYP1A2 }\end{array}$ & TQTC & \\
\hline & & Quetiapine & $\begin{array}{l}\uparrow \text { Quetiapine via } \\
\text { CYP3A4 }\end{array}$ & TQTC & $\begin{array}{l}\text { Cardiac monitor- } \\
\text { ing }\end{array}$ \\
\hline & & Ziprasidone & $\uparrow$ Que via CYP3A4 & & \\
\hline & & Clozapine & $\begin{array}{l}\text { Additive metabolic } \\
\text { toxicities }\end{array}$ & †QTc & $\begin{array}{l}\text { Consider alterna- } \\
\text { tive agents }\end{array}$ \\
\hline & \multirow{2}{*}{$\begin{array}{l}\text { First-generation } \\
\text { antipsychotics }\end{array}$} & Chlorpromazine & & TQTC & \\
\hline & & Pimozide & $\begin{array}{l}\uparrow \text { Pimozide via } \\
\text { CYP3A4 }\end{array}$ & †QTc & Contraindicated \\
\hline \multirow{6}{*}{ Anxiolytics } & \multirow{4}{*}{ Benzodiazepines } & Midazolam & $\begin{array}{l}\uparrow \text { Midazolam via } \\
\text { CYP3A4 }\end{array}$ & & Contraindicated \\
\hline & & Diazepam & $\uparrow$ Diazepam via 3A4 & & Dose reduction \\
\hline & & Alprazolam & $\uparrow$ Alprazolam via $3 \mathrm{~A} 4$ & & \multirow[t]{2}{*}{$\begin{array}{c}\text { Monitor sedation } \\
\text { and dose reduc- } \\
\text { tion }\end{array}$} \\
\hline & & Triazolam & $\downarrow$ Triazolam via 3A4 & & \\
\hline & Zolpidem & & $\uparrow$ Zolpidem via 3A4 & & $\begin{array}{l}\text { Not clinically } \\
\text { significant }\end{array}$ \\
\hline & Buspirone & & $\uparrow$ Buspirone via 3A4 & & $\begin{array}{c}\text { Dose adjustment } \\
\text { is not usually } \\
\text { necessary }\end{array}$ \\
\hline
\end{tabular}

NEUR:SCIENCE

SSRIs: Selective Serotonin Reuptake Inhibitors; SNRIs: Serotonin-Norepinephrine Reuptake Inhibitors; TCAs: Tricyclic Antidepressants; MAOIs: Monoamine Oxidase Inhibitors

with ritonavir (Greenblatt, von Moltke, Daily, Harmatz, \& Shader, 1999).

\subsubsection{Non-benzodiazepine}

Non-benzodiazepines are another sedative, hypnotic, and anxiolytics drugs, including zolpidem, eszopiclone, zaleplon, and ramelteon that is extensively metabolized via the CYP450 system. So, there is a potential for drug-drug interaction (Mandrioli, Mercolini, \& Augusta Raggi, 2010).

\subsubsection{Zolpidem}

Pathways for zolpidem metabolism are CYP3A4, CYP2C9, CYP1A2, CYP2D6, and CYP2C19 (Greenblatt et al., 2000; Wyen et al., 2008). The concomitant use of strong CYP3A4 inhibitors such as ritonavir may increase the serum concentration of zolpidem because CYP3A4 is an isoenzyme partially responsible for zolpidem me- tabolism (Valuck, 2004). In a pharmacokinetic study of healthy participants, ritonavir (200 mg twice daily for 2 days) increased the zolpidem ( $5 \mathrm{mg}$ single dose bedtime) AUC, and Cmax 28\% and 22\%, respectively and no pharmacodynamic changes related to zolpidem effects were found (Greenblatt et al., 2000).

\subsubsection{Buspirone}

Buspirone is an anxiolytic drug that its main pathway for metabolism is CYP3A4 isoenzyme. So one should be cautious and carefully monitor it in concomitant use with CYP3A4 inhibitors such as ritonavir. However, dose adjustment is not necessary (Clay \& Adams, 2003).

No interaction has been reported between anxiolytics and ribavirin, hydroxychloroquine, and chloroquine.

We should consider that the inhibitory effect of ritonavir on CYP2D6 is dose-dependent. Low-dose ritona- 
vir (100 mg two times a day) had only a slight effect on CYP2D6, but the curative dose of ritonavir (600 mg two times a day) had a greater effect (Smolders et al., 2016).

Azithromycin use, as one of the alternatives used in COVID-19 patients, needs caution because it may enhance the QTc-prolonging effect of QT-prolonging agents like citalopram, especially in patients at high risk (preexisting cardiac disease, old age, female sex, electrolyte imbalance, etc.) (Huang, Wu, Hsia, \& Yin Chen, 2007; Kezerashvili, Khattak, Barsky, Nazari, \& Fisher, 2007). No interaction has been reported between amantadine and chloroquine, hydroxychloroquine, ritonavir, and ribavirin. Table 1 summarizes the drug-drug interactions mentioned in this article.

\section{Conclusion}

Drug interactions are major challenges in the comorbidity of psychiatric disorders and COVID-19 infection resulting in the alteration of expected therapeutic outcomes. The risk of toxicity or lack of efficacy may occur due to a higher or lower plasma concentration of medications. Moreover, intensification of similar adverse effects might harm the patients. However, psychiatric medication could be used safely in combination with $\mathrm{CO}$ VID-19 pharmacotherapy if medications were selected with the least possibility of interaction and also careful monitoring. Psychiatrists should be aware of psychotropic drug interactions for optimal pharmacotherapy in the management of mental problems in COVID-19 patients.

\section{References}

Aarnoutse, R. E., Kleinnijenhuis, J., Koopmans, P. P., Touw, D. J., Wieling, J., Hekster, Y. A., et al. (2005). Effect of low-dose ritonavir (100 mg twice daily) on the activity of cytochrome P450 2D6 in healthy volunteers. Clinical Pharmacology \& Therapeutics, 78(6), 664-74. [DOI:10.1016/j.clpt.2005.09.001] [PMID]

Axelson, D. A., Perel, J. M., Birmaher, B., Rudolph, G. R. Nuss, S., Bridge, J., et al. (2002). Sertraline pharmacokinetics and dynamics in adolescents. Journal of the American Academy of Child \& Adolescent Psychiatry, 41(9), 1037-44. [DOI:10.1097/00004583-200209000-00003] [PMID]

Azuma, J., Hasunuma, T., Kubo, M., Miyatake, M., Koue, T., Higashi, K., et al. (2012). The relationship between clinical pharmacokinetics of aripiprazole and CYP2D6 genetic polymorphism: Effects of CYP enzyme inhibition by coadministration of paroxetine or fluvoxamine. European Journal of Clinical Pharmacology, 68(1), 29-37. [DOI:10.1007/s00228-011-1094-4] [PMID] [PMCID]
Bjornsson, T. D., Callaghan, J. T., Einolf, H. J., Fischer, V., Gan, L., Grimm, S., et al. (2003). The conduct of in vitro and in vivo drug-drug interaction studies: A Pharmaceutical Research and Manufacturers of America (PhRMA) perspective. Drug Metabolism and Disposition, 31(7), 815-32. [DOI:10.1124/ dmd.31.7.815] [PMID]

Boinpally, R., Gad, N., Gupta, S., \& Periclou, A. (2014). Influence of CYP3A4 induction/inhibition on the pharmacokinetics of vilazodone in healthy subjects. Clinical Therapeutics, 36(11), 1638-49. [DOI:10.1016/j.clinthera.2014.08.003] [PMID]

Bossini, L., Coluccia, A., Casolaro, I., Benbow, J., Amodeo, G., De Giorgi, R., et al. (2015). Off-label trazodone prescription: Evidence, benefits and risks. Current Pharmaceutical Design, 21(23), 3343-51. [DOI:10.2174/1381612821666150619092236] [PMID]

Cansu, D. U., \& Korkmaz, C. (2008). Hypoglycaemia induced by hydroxychloroquine in a non-diabetic patient treated for RA Rheumatology (Oxford, England), 47(3), 378-9. [DOI:10.1093/ rheumatology/kem378] [PMID]

Chen, C. J., Sugiyama, K., Kubo, H., Huang, C., \& Makino, S. (2004). Murine coronavirus nonstructural protein p28 arrests cell cycle in G0/G1 phase. Journal of Virology, 78(19), 10410-9. [DOI:10.1128/JVI.78.19.10410-10419.2004] [PMID] [PMCID]

Clay, P. G., \& Adams, M. M. (2003). Pseudo-Parkinson disease secondary to ritonavir-buspirone interaction. Annals of Pharmacotherapy, 37(2), 202-5. [DOI:10.1177/10600280030370020 7] [PMID]

Cooper, A. J., \& Ashcroft, G. (1966). Potentiation of insulin hypoglycæmia by MA 0.1. Antidepressant drugs. The Lancet, 287(7434), 407-9. [DOI:10.1016/S0140-6736(66)91399-7]

Corbett, A. H., Lim, M. L., \& Kashuba, A. D. (2002). Kaletra (lopinavir/ritonavir). Annals of Pharmacotherapy, 36(7-8), 1193 203. [DOI:10.1345/aph.1A363] [PMID]

De-Heer, R., \& Doherty, T. (2018). A case of hydroxychloroquine induced hypoglycaemia in a non-diabetic patient. Journal of Rheumatic Diseases and Treatment, 4(3), 066. [DOI:10.23937/2469-5726/1510066]

Valuck, R. (2004). Selective serotonin reuptake inhibitors: A class review. P\&T Community, 29(4), 234-43. https:/ /www. ptcommunity.com/journal/article/archives/2004/4/234/ selective-serotonin-reuptake-inhibitors-class-review

Derijks, H. J., Heerdink, E. R., De Koning, F. H., Janknegt, R. Klungel, O. H., \& Egberts, A. C. (2008). The association between antidepressant use and hypoglycaemia in diabetic patients: A nested case-control study. Pharmacoepidemiology and Drug Safety, 17(4), 336-44. [DOI:10.1002/pds.1562] [PMID]

Derijks, H. J., Meyboom, R. H., Heerdink, E. R., De Koning, F. H., Janknegt, R., Lindquist, M., et al. (2008). The association between antidepressant use and disturbances in glucose homeostasis: Evidence from spontaneous reports. European Journal of Clinical Pharmacology, 64(5), 531-8. [DOI:10.1007/ s00228-007-0441-y] [PMID] [PMCID]

DeSilva, K. E., Le Flore, D. B., Marston, B. J., \& Rimland, D. (2001). Serotonin syndrome in HIV-infected individuals receiving antiretroviral therapy and fluoxetine. Aids, 15(10), 1281-5. [DOI:10.1097/00002030-200107060-00010] [PMID] 
DeVane, C. L., \& Gill, H. S. (1997). Clinical pharmacokinetics of fluvoxamine: Applications to dosage regimen design. The Journal of Clinical Psychiatry, 58 Suppl 5, 7-14. [PMID]

Di Paola, L., \& Giuliani, A. (2020). Mapping active allosteric loci SARS-CoV spike proteins by means of protein contact networks. arXiv:2003.05200. https://arxiv.org/abs/2003.05200

DiCenzo, R., Peterson, D., Cruttenden, K., Morse, G., Riggs, G. Gelbard, H., et al. (2004). Effects of valproic acid coadministration on plasma efavirenz and lopinavir concentrations in human immunodeficiency virus-infected adults. Antimicrobial Agents and Chemotherapy, 48(11), 4328-31. [DOI:10.1128/ AAC.48.11.4328-4331.2004] [PMID] [PMCID]

Ducharme, J., \& Farinotti, R. (1996). Clinical pharmacokinetics and metabolism of chloroquine. Clinical Pharmacokinetics, 31(4), 257-74. [DOI:10.2165/00003088-199631040-00003] [PMID]

Dybul, M., Fauci, A. S., Bartlett, J. G., Kaplan, J. E., Pau, A. K., \& Panel on Clinical Practices for Treatment of HIV. (2002). Guidelines for using antiretroviral agents among HIV-infected adults and adolescents. Annals of Internal Medicine, 137(5 Pt 2), 381-433. [DOI:10.7326/0003-4819-137-5_Part_2200209031-00001] [PMID]

Ethell, B. T., Anderson, G. D., \& Burchell, B. (2003). The effect of valproic acid on drug and steroid glucuronidation by expressed human UDP-glucuronosyltransferases. Biochemical Pharmacology, 65(9), 1441-9. [DOI:10.1016/S00062952(03)00076-5]

Frye, R., Bertz, R., Granneman, G. R., Qian, J., Lamm, J., Dennis, S., \& Valdes, J. (1997). Effect of ritonavir on the pharmacokinetics and pharmacodynamics of alprazolam. Paper presented at Interscience Conference on Antimicrobial Agents and Chemotherapy, Metro Toronto, Canada, 28 September-1 October 1997.

American Psychiatric Association. (2000). Practice guideline for the treatment of patients with major depressive disorder (revision). The American journal of psychiatry, 157(4 Suppl), 1-45.

Ghaeli, P., Shahsavand, E., Mesbahi, M., Kamkar, M. Z., Sadeghi, M., \& Dashti-Khavidaki, S. (2004). Comparing the effects of 8-week treatment with fluoxetine and imipramine on fasting blood glucose of patients with major depressive disorder. Journal of Clinical Psychopharmacology, 24(4), 386-8. [DOI:10.1097/01.jcp.0000132441.27854.0d] [PMID]

Gillman, P. K. (2007). Tricyclic antidepressant pharmacology and therapeutic drug interactions updated. British Journal of Pharmacology, 151(6), 737-48. [DOI:10.1038/sj.bjp.0707253] [PMID] [PMCID]

Goodlet, K. J., Zmarlicka, M. T., \& Peckham, A. M. (2019). Drugdrug interactions and clinical considerations with co-administration of antiretrovirals and psychotropic drugs. CNS Spectrums, 24(3), 287-312. [DOI:10.1017/S109285291800113X] [PMID]

Gould, T. D., Chen, G., \& Manji, H. K. (2002). Mood stabilizer psychopharmacology. Clinical Neuroscience Research, 2(3-4), 193-212. [DOI:10.1016/S1566-2772(02)00044-0]

Goyal, K., Chauhan, P., Chhikara, K., Gupta, P., \& Singh, M. P. (2020). Fear of COVID 2019: First suicidal case in India. Asian Journal of Psychiatry, 49, 101989. [DOI:10.1016/j. ajp.2020.101989] [PMID] [PMCID]
Goyal, V., \& Bordia, A. (1995). The hypoglycemic effect of chloroquine. The Journal of the Association of Physicians of India, 43(1), 17-8. [PMID]

Greenblatt, D. J., von Moltke, L. L., Harmatz, J. S., Durol, A. L. Daily, J. P., Graf, J. A., et al. (2000). Differential impairment of triazolam and zolpidem clearance by ritonavir. Journal of Acquired Immune Deficiency Syndromes, 24(2), 129-36. [DOI:10.1097/00126334-200006010-00007]

Greenblatt, D. J., von Moltke, L. L., Daily, J. P., Harmatz, J. S., \& Shader, R. I. (1999). Extensive impairment of triazolam and alprazolam clearance by short-term low-dose ritonavir: The clinical dilemma of concurrent inhibition and induction. Journal of Clinical Psychopharmacology, 19(4), 293-6. [DOI:10.1097/00004714-199908000-00001] [PMID]

Greenblatt, D. J., von Moltke, L. L., Harmatz, J. S., Fogelman, S M., Chen, G., Graf, J. A., et al. (2003). Short-term exposure to low-dose ritonavir impairs clearance and enhances adverse effects of trazodone. The Journal of Clinical Pharmacology, 43(4), 414-22. [DOI:10.1177/0091270003251864] [PMID]

Griffin, C. E., Kaye, A. M., Bueno, F. R., \& Kaye, A. D. (2013), Benzodiazepine pharmacology and central nervous systemmediated effects. The Ochsner Journal, 13(2), 214-23. [PMID] [PMCID]

Guan, W. J., Ni, Z. Y., Hu, Y., Liang, W. H., Ou, C. Q., He, J. X., et al. (2020). Clinical characteristics of coronavirus disease 2019 in China. The New England Journal of Medicine, 382(18), 1708-20. [DOI:10.1056/NEJMoa2002032] [PMID] [PMCID]

Gutierrez, M., \& Abramowitz, W. (2001). Lack of effect of a single dose of ketoconazole on the pharmacokinetics of citalopram. Pharmacotherapy, 21(2), 163-8. [DOI:10.1592/ phco.21.2.163.34101] [PMID]

Gutierrez, M. M., Rosenberg, J., \& Abramowitz, W. (2003). An evaluation of the potential for pharmacokinetic interaction between escitalopram and the cytochrome P450 3A4 inhibitor ritonavir. Clinical Therapeutics, 25(4), 1200-10. [DOI:10.1016/ S0149-2918(03)80076-0]

Halaby, M. J., Kastein, B. K., \& Yang, D. Q. (2013). Chloroquine stimulates glucose uptake and glycogen synthase in muscle cells through activation of Akt. Biochemical and Biophysical Research Communications, 435(4), 708-13. [DOI:10.1016/j. bbrc.2013.05.047] [PMID]

Han, S., Park, H. S., Lee, Y. H., Lee, B. W., Kang, E. S., \& Cha, B. S. (2016). Paroxetine-induced hypoglycemia in type 2 diabetic patient. The Ewha Medical Journal, 39(1), 14-6. [DOI:10.12771/emj.2016.39.1.14]

Hendset, M., Hermann, M., Lunde, H., Refsum, H., \& Molden E. (2007). Impact of the CYP2D6 genotype on steady-state serum concentrations of aripiprazole and dehydroaripiprazole European Journal Of Clinical Pharmacology, 63(12), 1147-51 [DOI:10.1007/s00228-007-0373-6] [PMID]

Hesse, L. M., Greenblatt, D. J., von Moltke, L. L., \& Court, M. H. (2006). Ritonavir has minimal impact on the pharmacokinetic disposition of a single dose of bupropion administered to human volunteers. The Journal of Clinical Pharmacology, 46(5), 567-76. [DOI:10.1177/0091270006286981] [PMID]

Hesse, L. M., von Moltke, L. L., \& Greenblatt, D. J. (2003). Clinically important drug interactions with zopiclone, zolpidem and zaleplon. CNS Drugs, 17(7), 513-32. [DOI:10.2165/00023210200317070-00004] [PMID] 
Hesse, L. M., von Moltke, L. L., Shader, R. I., \& Greenblatt, D. J. (2001). Ritonavir, efavirenz, and nelfinavir inhibit CYP2B6 activity in vitro: Potential drug interactions with bupropion. Drug Metabolism and Disposition, 29(2), 100-2. [PMID]

Hill, L., \& Lee, K. C. (2013). Pharmacotherapy considerations in patients with HIV and psychiatric disorders: Focus on antidepressants and antipsychotics. Annals of Pharmacotherapy, 47(1), 75-89. [DOI:10.1345/aph.1R343] [PMID]

Hogeland, G. W., Swindells, S., McNabb, J. C., Kashuba, A. D. M., Yee, G. C., \& Lindley, C. M. (2007). Lopinavir/ritonavir reduces bupropion plasma concentrations in healthy subjects. Clinical Pharmacology \& Therapeutics, 81(1), 69-75. [DOI:10.1038/sj.clpt.6100027] [PMID]

Horst, W. D., \& Preskorn, S. H. (1998). Mechanisms of action and clinical characteristics of three atypical antidepressants: Venlafaxine, nefazodone, bupropion. Journal of Affective Disorders, 51(3), 237-54. [DOI:10.1016/S0165-0327(98)00222-5]

Hou, X. J., Xu, J. H., Wang, J., \& Yu, Y. Y. (2013). Can antidepressants prevent pegylated interferon- $\alpha /$ ribavirin-associated depression in patients with chronic hepatitis C: Meta-analysis of randomized, double-blind, placebo-controlled trials? PLoS One, 8(10), e76799. [DOI:10.1371/journal.pone.0076799] [PMID] [PMCID]

Howell, C., Wilson, A. D., \& Waring, W. (2007). Cardiovascular toxicity due to venlafaxine poisoning in adults: A review of 235 consecutive cases. British Journal of Clinical Pharmacology, 64(2), 192-7. [DOI:10.1111/j.1365-2125.2007.02849.x] [PMID] [PMCID]

Hsu, A., Granneman, G. R., \& Bertz, R. J. (1998). Ritonavir. Clinical Pharmacokinetics, 35(4), 275-91. [DOI:10.2165/00003088199835040-00002] [PMID]

Huang, B. H., Wu, C. H., Hsia, C. P., \& Chen, C. Y. (2007) Azithromycin-induced torsade de pointes. Pacing and Clinical Electrophysiology, 30(12), 1579-82. [DOI:10.1111/j.15408159.2007.00912.x] [PMID]

Ieiri, I., Tsunemitsu, S., Maeda, K., Ando, Y., Izumi, N., Kimura M., et al. (2013). Mechanisms of pharmacokinetic enhancement between ritonavir and saquinavir; micro/small dosing tests using midazolam (CYP3A4), fexofenadine (P-glycoprotein), and pravastatin (OATP1B1) as probe drugs. The Journal of Clinical Pharmacology, 53(6), 654-61. [DOI:10.1002/ jcph.62] [PMID]

Jacobs, B. S., Colbers, A. P., Velthoven-Graafland, K., Schouwenberg, B. J., \& Burger, D. M. (2014). Effect of fosamprenavir/ritonavir on the pharmacokinetics of single-dose olanzapine in healthy volunteers. International Journal of Antimicrobial Agents, 44(2), 173-7. [DOI:10.1016/j.ijantimii cag.2014.03.014] [PMID]

Jernigan, M. G., Kipp, G. M., Rather, A., Jenkins, M. T., \& Chung, A. M. (2013). Clinical implications and management of drugdrug interactions between antiretroviral agents and psychotropic medications. Mental Health Clinician, 2(9), 274-85. [DOI:10.9740/mhc.n139874]

Jin, X., Potter, B., Luong, T. L., Nelson, J., Vuong, C., Potter, C., et al. (2016). Pre-clinical evaluation of CYP 2D6 dependent drug-drug interactions between primaquine and SSRI/SNRI antidepressants. Malaria Journal, 15(1), 280. [DOI:10.1186/ s12936-016-1329-z] [PMID] [PMCID]
Jornil, J., Jensen, K. G., Larsen, F., \& Linnet, K. (2010). Identification of cytochrome P450 isoforms involved in the metabolism of paroxetine and estimation of their importance for human paroxetine metabolism using a population-based simulator. Drug Metabolism and Disposition, 38(3), 376-85. [DOI:10.1124/dmd.109.030551] [PMID]

Jover, F., Cuadrado, J. M., Andreu, L., \& Merino, J. (2002). Reversible coma caused by risperidone-ritonavir interaction. Clinical Neuropharmacology, 25(5), 251-3. [DOI:10.1097/00002826200209000-00004] [PMID]

Kakuda, T. N., Schöller-Gyüre, M., \& Hoetelmans, R. M. W. (2011). Pharmacokinetic interactions between etravirine and non-antiretroviral drugs. Clinical Pharmacokinetics, 50(1), 2539. [DOI:10.2165/11534740-000000000-00000] [PMID]

Kelly, D. V., Béïque, L. C., \& Bowmer, M. I. (2002). Extrapyramidal symptoms with ritonavir/indinavir plus risperidone. Annals of Pharmacotherapy, 36(5), 827-30. [DOI:10.1345/ aph.1A335] [PMID]

Kezerashvili, A., Khattak, H., Barsky, A., Nazari, R., \& Fisher, J. D. (2007). Azithromycin as a cause of QT-interval prolongation and torsade de pointes in the absence of other known precipitating factors. Journal of Interventional Cardiac Electrophysiology, 18(3), 243-6. [DOI:10.1007/s10840-007-9124-y] [PMID]

Kharasch, E. D., Mitchell, D., Coles, R., \& Blanco, R. (2008). Rapid clinical induction of hepatic cytochrome P4502B6 activity by ritonavir. Antimicrobial Agents and Chemotherapy, 52(5), 1663-9. [DOI:10.1128/AAC.01600-07] [PMID] [PMCID]

Khoza, S., \& Barner, J. C. (2011). Glucose dysregulation associated with antidepressant agents: An analysis of 17 published case reports. International Journal of Clinical Pharmacy, 33(3), 484-92. [DOI:10.1007/s11096-011-9507-0] [PMID]

Kim, J. A. A., Chang, J. S., Abela, G. S. (2013). An Association of Takotsubo Cardiomyopathy and Use of Antidepressants. Paper presented at $18^{\text {th }}$ World Congress on Heart Disease, Vancouver, Canada, 26-29 July 2013,

Kirby, B. J., Collier, A. C., Kharasch, E. D., Whittington, D., Thummel, K. E., \& Unadkat, J. D. (2011). Complex drug interactions of HIV protease inhibitors 1: Inactivation, induction, and inhibition of cytochrome P450 3A by ritonavir or nelfinavir. Drug Metabolism and Disposition, 39(6), 1070-8. [DOI:10.1124/dmd.110.037523] [PMID] [PMCID]

Knox, T. A., Oleson, L., von Moltke, L. L., Kaufman, R. C., Wanke, C. A., \& Greenblatt, D. J. (2008). Ritonavir greatly impairs CYP3A activity in HIV infection with chronic viral hepatitis. JAIDS Journal of Acquired Immune Deficiency Syndromes, 49(4), 358-68. [DOI:10.1097/ QAI.0b013e31818c7efe] [PMID]

Kotlyar, M., Brauer, L. H., Tracy, T. S., Hatsukami, D. K., Harris, J., Bronars, C. A., et al. (2005). Inhibition of CYP2D6 activity by bupropion. Journal of Clinical Psychopharmacology, 25(3) 226-9. [DOI:10.1097/01.jcp.0000162805.46453.e3] [PMID]

Kräuhenbühl, S., Sauter, B., Kupferschmidt, H., Krause, M., Wyss, P. A., \& Meier, P. J. (1995). Reversible QT prolongation with torsades de pointes in a patient with pimozide intoxication. The American Journal of the Medical Sciences, 309(6), 315-6. [DOI:10.1097/00000441-199506000-00003] [PMID]

Kronbach, T., Mathys, D., Umeno, M., Gonzalez, F. J., \& Meyer, U. A. (1989). Oxidation of midazolam and triazolam by hu- 
man liver cytochrome P450IIIA4. Molecular Pharmacology, 36(1), 89-96. http://molpharm.aspetjournals.org/content/36/1/89

Kuhn, R. (1958). The treatment of depressive states with G 22355 (imipramine hydrochloride). American Journal of Psychiatry, 115(5), 459-64. [DOI:10.1176/ajp.115.5.459] [PMID]

Lai, C. C., Shih, T. P., Ko, W. C., Tang, H. J., \& Hsueh, P. R. (2020). Severe acute respiratory syndrome coronavirus 2 (SARS-CoV-2) and corona virus disease-2019 (COVID-19): The epidemic and the challenges. International Journal of Antimicrobial Agents, 55(3), 105924. [DOI:10.1016/j.ijantimii cag.2020.105924] [PMID] [PMCID]

Lally, J., \& MacCabe, J. H. (2015). Antipsychotic medication in schizophrenia: A review. British Medical Bulletin, 114(1), 16979. [DOI:10.1093/bmb/ldv017] [PMID]

Levenson, J. L. (1999). Prolonged QT interval after trazodone overdose. American Journal of Psychiatry, 156(6), 969-70. [DOI:10.1176/ajp.156.6.969a] [PMID]

Levêque, D., Lemachatti, J., Nivoix, Y., Coliat, P., Santucci, R., Ubeaud-Séquier, G., et al. (2010). [Mechanisms of pharmacokinetic drug-drug interactions [French)]. La Revue de Médecine Interne, 31(2), 170-9. [DOI:10.1016/j.revmed.2009.07.009] [PMID]

Li, W., Yang, Y., Liu, Z. H., Zhao, Y. J., Zhang, Q., Zhang, L., et al. (2020). Progression of mental health services during the COVID-19 outbreak in China. International Journal of Biological Sciences, 16(10), 1732-8. [DOI:10.7150/ijbs.45120] [PMID] [PMCID]

Lim, M. L., Min, S. S., Eron, J. J., Bertz, R. J., Robinson, M., Gaedigk, A., et al. (2004). Coadministration of lopinavir/ ritonavir and phenytoin results in two-way drug interaction through cytochrome P-450 induction. JAIDS Journal of Acquired Immune Deficiency Syndromes, 36(5), 1034-40. [DOI:10.1097/00126334-200408150-00006] [PMID]

Lindh, J. D., Annas, A., Meurling, L., Dahl, M. L., \& Ayman, A. S. (2003). Effect of ketoconazole on venlafaxine plasma concentrations in extensive and poor metabolisers of debrisoquine. European Journal of Clinical Pharmacology, 59(5-6), 401-6. [DOI:10.1007/s00228-003-0627-x] [PMID]

Liston, H. L., DeVane, C. L., Boulton, D. W., Risch, S. C., Markowitz, J. S., \& Goldman, J. (2002). Differential time course of cytochrome P450 2D6 enzyme inhibition by fluoxetine, sertraline, and paroxetine in healthy volunteers. Journal of Clinical Psychopharmacology, 22(2), 169-73. [DOI:10.1097/00004714200204000-00010] [PMID]

Makanjuola, R. O., Dixon, P. A., \& Oforah, E. (1988). Effects of antimalarial agents on plasma levels of chlorpromazine and its metabolites in schizophrenic patients. Tropical and Geographical Medicine, 40(1), 31-3. [PMID]

Mandrioli, R., Mercolini, L., \& Augusta Raggi, M. (2010). Metabolism of benzodiazepine and non-benzodiazepine anxiolytichypnotic drugs: An analytical point of view. Current Drug Metabolism, 11(9), 815-29. [DOI:10.2174/13892001079432888 7] [PMID]

Manini, A. F., Raspberry, D., Hoffman, R. S., \& Nelson, L. S. (2007). QT prolongation and torsades de pointes following overdose of ziprasidone and amantadine. Journal of Medical Toxicology, 3(4), 178-81. [DOI:10.1007/BF03160936] [PMID] [PMCID]
Margolis, J. M., O'Donnell, J. P., Mankowski, D. C., Ekins, S., \& Obach, R. S. (2000). (R)-, (S)-, and racemic fluoxetine N-demethylation by human cytochrome P450 enzymes. Drug Metabolism and Disposition, 28(10), 1187-91. [PMID]

Mathias, A. A., West, S., Hui, J., \& Kearney, B. P. (2009). Doseresponse of ritonavir on hepatic CYP3A activity and elvitegravir oral exposure. Clinical Pharmacology \& Therapeutics, 85(1), 64-70. [DOI:10.1038/clpt.2008.168] [PMID]

Meid, A. D., Bighelli, I., Mächler, S., Mikus, G., Carrà, G., Castellazzi, M., et al. (2017). Combinations of QTc-prolonging drugs: Towards disentangling pharmacokinetic and pharmacodynamic effects in their potentially additive nature. Therapeutic Advances in Psychopharmacology, 7(12), 251-64. [DOI:10.1177/2045125317721662] [PMID] [PMCID]

Mostafavi, H. (1998). Effect of chloroquine on blood glucose levels in patients with non insulin dependent diabetes mellitus. Acta Medica Iranica, 36(2), 109-12. http:/ /acta.tums.ac.ir/index.php/acta/article/view/1753

Nelson, C. (2020). Serotonin-Norepinephrine Reuptake Inhibitors (SNRIs): Pharmacology, administration, and side effects. Retrieved from https://www.uptodate.com/contents/serotonin-norepinephrine-reuptake-inhibitors-snris-pharmacology-administration-and-side-effects?

Nguyen, H. C., Nguyen, M. H., Do, B. N., Tran, C. Q., Nguyen, T. T. P., Pham, K. M., et al. (2020). People with suspected COVID-19 symptoms were more likely depressed and had lower health-related quality of life: The potential benefit of health literacy. Journal of Clinical Medicine, 9(4), E965. [DOI:10.3390/jcm9040965] [PMID]

Norman, E. S., Dunn, G., Bakker, K., Allen, D. M., \& De Albuquerque, R. C. (2013). Water security assessment: Integrating governance and freshwater indicators. Water Resources Management, 27(2), 535-51. [DOI:10.1007/s11269-012-0200-4]

Ogu, C. C., \& Maxa, J. L. (2000). Drug interactions due to cytochrome P450. Proceedings (Baylor University. Medical Center), 13(4), 421-3. [DOI:10.1080/08998280.2000.11927719] [PMID] [PMCID]

Ouellet, D., Hsu, A., Qian, J., Lamm, J. E., Cavanaugh, J. H., Leonard, J. M., et al. (1998). Effect of fluoxetine on pharmacokinetics of ritonavir. Antimicrobial Agents and Chemotherapy, 42(12), 3107-12. [DOI:10.1128/AAC.42.12.3107] [PMID] [PMCID]

Park, J., Vousden, M., Brittain, C., McConn, D. J., Iavarone, L., Ascher, J., et al. (2010). Dose-related reduction in bupropion plasma concentrations by ritonavir The Journal of Clinical Pharmacology, 50(10), 1180-7. [DOI:10.1177/0091270009359524] [PMID]

Penzak, S. R., Hon, Y. Y., Lawhorn, W. D., Shirley, K. L., Spratlin, V., \& Jann, M. W. (2002). Influence of ritonavir on olanzapine pharmacokinetics in healthy volunteers. Journal of Clinical Psychopharmacology, 22(4), 366-70. [DOI:10.1097/00004714200208000-00006] [PMID]

Phillips, R. E., Looareesuwan, S., White, N. J., Chanthavanich P., Karbwang, J., Supanaranond, W., et al. (1986). Hypoglycaemia and antimalarial drugs: Quinidine and release of insulin. British Medical Journal (Clinical research ed.), 292(6531), 1319-21. [DOI:10.1136/bmj.292.6531.1319] [PMID] [PMCID]

Pollack, T. M., McCoy, C., \& Stead, W. (2009). Clinically significant adverse events from a drug interaction between quetia- 
pine and atazanavir-ritonavir in two patients. Pharmacotherapy, 29(11), 1386-91. [DOI:10.1592/phco.29.11.1386] [PMID]

Preskorn, S. H. (1997). Clinically relevant pharmacology of selective serotonin reuptake inhibitors. An overview with emphasis on pharmacokinetics and effects on oxidative drug metabolism. Clinical Pharmacokinetics, 32 Suppl 1, 1-21. [DOI:10.2165/00003088-199700321-00003] [PMID]

Preskorn, S. H. (2012). Clinically important differences in the pharmacokinetics of the ten newer "atypical" antipsychotics: Part 2. Metabolism and elimination. Journal of Psychiatric Practice, 18(5), 361-8. [DOI:10.1097/01.pra.0000419820.68128. ad] [PMID]

Projean, D., Baune, B., Farinotti, R., Flinois, J. P., Beaune, P., Taburet, A. M., et al. (2003). In vitro metabolism of chloroquine: Identification of CYP2C8, CYP3A4, and CYP2D6 as the main isoforms catalyzing $\mathrm{N}$-desethylchloroquine formation. Drug Metabolism and Disposition, 31(6), 748-54. [DOI:10.1124/dmd.31.6.748] [PMID]

Riss, J., Cloyd, J., Gates, J., \& Collins, S. (2008). Benzodiazepines in epilepsy: Pharmacology and pharmacokinetics. Acta Neurologica Scandinavica, 118(2), 69-86. [DOI:10.1111/j.16000404.2008.01004.x] [PMID]

Dhali, R. S., Banerjee, P., Munshi, S., \& Chaudhuri, P. R. (2015). Hypoglycemic episodes in a case of prementrual dysphoric disorder on sertraline. Indian Journal of Pharmacology, 47(5), 567-8. [DOI:10.4103/0253-7613.165193] [PMID] [PMCID]

Schmitt, C., Hofmann, C., Riek, M., Patel, A., \& Zwanziger, E. (2009). Effect of saquinavir-ritonavir on cytochrome P450 3A4 activity in healthy volunteers using midazolam as a probe. Pharmacotherapy, 29(10), 1175-81. [DOI:10.1592/ phco.29.10.1175] [PMID]

Sheehan, J., Sliwa, J., Amatniek, J., Grinspan, A., \& Canuso, C. (2010). Atypical antipsychotic metabolism and excretion. Current Drug Metabolism, 11(6), 516-25. [DOI:10.2174/13892001 0791636202] [PMID]

Sheehan, N. L., Brouillette, M. J., Delisle, M. S., \& Allan, J. (2006) Possible interaction between lopinavir/ritonavir and valproic acid exacerbates bipolar disorder. Annals of Pharmacotherapy, 40(1), 147-50. [DOI:10.1345/aph.1G418] [PMID]

Shelton, R. C. (2019). Serotonin and norepinephrine reuptake inhibitors. Handbook of Experimental Pharmacology, 250, 145-80. [DOI:10.1007/164_2018_164] [PMID]

Shojania, K., Koehler, B. E., \& Elliott, T. (1999). Hypoglycemia induced by hydroxychloroquine in a type II diabetic treated for polyarthritis. The Journal of Rheumatology, 26(1), 195-6. [PMID]

Skinner, M. H., Kuan, H. Y., Pan, A., Sathirakul, K., Knadler, M. P., Gonzales, C. R., et al. (2003). Duloxetine is both an inhibitor and a substrate of cytochrome P4502D6 in healthy volunteers. Clinical Pharmacology \& Therapeutics, 73(3), 170-7. [DOI:10.1067/mcp.2003.28] [PMID]

Smolders, E. J., de Kanter, C. T. M. M., de Knegt, R. J., van der Valk, M., Drenth, J. P. H., \& Burger, D. M. (2016). Drug-drug interactions between direct-acting antivirals and psychoactive medications. Clinical Pharmacokinetics, 55(12), 1471-94. [DOI:10.1007/s40262-016-0407-2] [PMID] [PMCID]

Spina, E., Pisani, F., \& de Leon, J. (2016). Clinically significant pharmacokinetic drug interactions of antiepileptic drugs with new antidepressants and new antipsychotics. Pharmacological Research, 106, 72-86. [DOI:10.1016/j.phrs.2016.02.014] [PMID]

Spina, E., Santoro, V., \& D'Arrigo, C. (2008). Clinically relevant pharmacokinetic drug interactions with second-generation antidepressants: An update. Clinical Therapeutics, 30(7), 1206-27. [DOI:10.1016/S0149-2918(08)80047-1]

Suzuki, T., Mihara, K., Nakamura, A., Nagai, G., Kagawa, Sh. Nemoto, K., et al. (2011). Effects of the CYP2D6* 10 allele on the steady-state plasma concentrations of aripiprazole and its active metabolite, dehydroaripiprazole, in Japanese patients with schizophrenia. Therapeutic Drug Monitoring, 33(1), $21-$ 4. [DOI:10.1097/FTD.0b013e3182031021] [PMID]

Thompson, A., Silverman, B., Dzeng, L., \& Treisman, G. (2006). Psychotropic medications and HIV. Clinical Infectious Diseases, 42(9), 1305-10. [DOI:10.1086/501454] [PMID]

Tönnesmann, E., Kandolf, R., \& Lewalter, T. (2013). Chloroquine cardiomyopathy-a review of the literature. Immunopharmacology and Immunotoxicology, 35(3), 434-42. [DOI:10.3109/0 8923973.2013.780078] [PMID]

Tuite, A. R., Bogoch, I., Sherbo, R., Watts, A., Fisman, D. N., \& Khan, K. (2020). Estimation of COVID-2019 burden and potential for international dissemination of infection from Iran. medRxiv. [DOI:10.1101/2020.02.24.20027375]

Unübol, M., Ayhan, M., \& Guney, E. (2011). Hypoglycemia induced by hydroxychloroquine in a patient treated for rheumatoid arthritis. Journal of Clinical Rheumatology, 17(1), 46-7. [DOI:10.1097/RHU.0b013e3182098e1f] [PMID]

Urichuk, L., Prior, T. I., Dursun, S., \& Baker, G. (2008). Metabolism of atypical antipsychotics: Involvement of cytochrome p450 enzymes and relevance for drug-drug interactions. Current Drug Metabolism, 9(5), 410-8. [DOI:10.2174/1389200087 84746373] [PMID]

van der Lee, M. J., Blenke, A. A. M., Rongen, G. A., Verweyvan Wissen, C. P. W. G. M., Koopmans, P. P., Pharo, C., et al. (2007). Interaction study of the combined use of paroxetine and fosamprenavir-ritonavir in healthy subjects. Antimicrobial Agents and Chemotherapy, 51(11), 4098-104. [DOI:10.1128/AAC.01243-06] [PMID] [PMCID]

van der Lee, M. J., Dawood, L., ter Hofstede, H. J. M., de GraaffTeulen, M. J. A., van Ewijk-Beneken Kolmer, E. W., Caliskan-Yassen, N., et al. (2006). Lopinavir/ritonavir reduces lamotrigine plasma concentrations in healthy subjects. Clinical Pharmacology \& Therapeutics, 80(2), 159-68. [DOI:10.1016/j. clpt.2006.04.014] [PMID]

van Harten, J. (1995). Overview of the pharmacokinetics of fluvoxamine. Clinical Pharmacokinetics, 29 Suppl 1, 1-9. [DOI:10.2165/00003088-199500291-00003] [PMID]

von Moltke, L. L., Greenblatt, D. J., Giancarlo, G. M., Granda, B. W., Harmatz, J. S., \& Shader, R. I. (2001). Escitalopram (S-citalopram) and its metabolites in vitro: Cytochromes mediating biotransformation, inhibitory effects, and comparison to Rcitalopram. Drug Metabolism and Disposition, 29(8), 1102-9. [PMID]

Wickström, L., \& Pettersson, K. (1964). Treatment of diabetics with monoamine-oxidase inhibitors. The Lancet, 284(7367) 995-7. [DOI:10.1016/S0140-6736(64)90936-5] 
Wijesinghe, R. (2016). A review of pharmacokinetic and pharmacodynamic interactions with antipsychotics. Mental Health Clinician, 6(1), 21-7. [DOI:10.9740/mhc.2016.01.021] [PMID] [PMCID]

Wu, Z., \& McGoogan, J. M. (2020). Characteristics of and important lessons from the coronavirus disease 2019 (COVID-19) outbreak in China: Summary of a report of 72314 cases from the Chinese Center for Disease Control and Prevention. JAMA, 323(13), 1239-42. [DOI:10.1001/jama.2020.2648]

Wyen, C., Fuhr, U., Frank, D., Aarnoutse, R. E., Klaassen, T., Lazar, A., et al. (2008). Effect of an antiretroviral regimen containing ritonavir boosted lopinavir on intestinal and hepatic CYP3A, CYP2D6 and P-glycoprotein in HIV-infected patients. Clinical Pharmacology \& Therapeutics, 84(1), 75-82. [DOI:10.1038/sj.clpt.6100452] [PMID]

Xue, C., Zhang, X., \& Cai, W. (2017). Prediction of drug-drug interactions with bupropion and its metabolites as CYP2D6 inhibitors using a physiologically-based pharmacokinetic model. Pharmaceutics, 10(1), 1. [DOI:10.3390/pharmaceut tics10010001] [PMID] [PMCID]

Yamada, M., \& Yasuhara, H. (2004). Clinical pharmacology of MAO inhibitors: Safety and future. Neurotoxicology, 25(1-2), 215-21. [DOI:10.1016/S0161-813X(03)00097-4]

Yeh, R. F., Gaver, V. E., Patterson, K. B., Rezk, N. L., BaxterMeheux, F., Blake, M. J., et al. (2006). Lopinavir/ritonavir induces the hepatic activity of cytochrome P450 enzymes CYP2C9, CYP2C19, and CYP1A2 but inhibits the hepatic and intestinal activity of CYP3A as measured by a phenotyping drug cocktail in healthy volunteers. Journal of Acquired Immune Deficiency Syndromes, 42(1), 52-60. [DOI:10.1097/01. qai.0000219774.20174.64] [PMID]

Zalma, A., von Moltke, L. L., Granda, B. W., Harmatz, J. S., Shader, R. I., \& Greenblatt, D. J. (2000). In vitro metabolism of trazodone by CYP3A: Inhibition by ketoconazole and human immunodeficiency viral protease inhibitors. Biological Psychiatry, 47(7), 655-61. [DOI:10.1016/S0006-3223(99)00176-6] 